\title{
Biology of the Blood Crayfish, Euastacus gumar Morgan 1997, a small freshwater crayfish from the Richmond Range, northeastern New South Wales
}

\section{Jason Coughran}

Environmental Futures Centre, Griffith School of Environment, Gold Coast Campus, Griffith University, Queensland, Australia, 4222.

j.coughran@griffith.edu.au

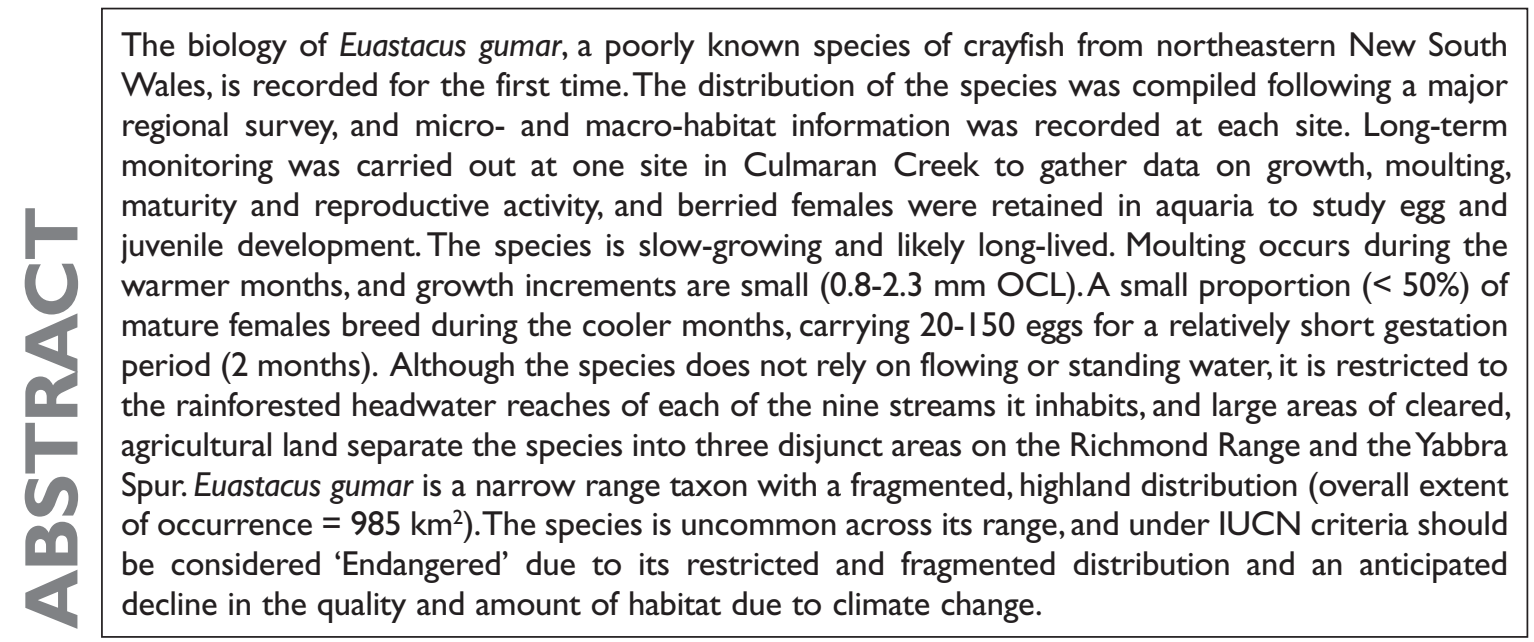

\section{Introduction}

Euastacus gumar (Figure 1) was first described by Morgan (1997) from two proximal sites on the Richmond Range (Gorge Creek and Culmaran Creek), northeastern New South Wales. Morgan recorded the land-use as State Forest, although the co-ordinates given correspond to a cattle station. The property was previously (ca. 1950s) under dairy cattle, switching to beef cattle in more recent years (A. Leonard, station manager, pers. comm.). The property abuts the Richmond Range National Park (State Forest at the time of Morgan's collection), within

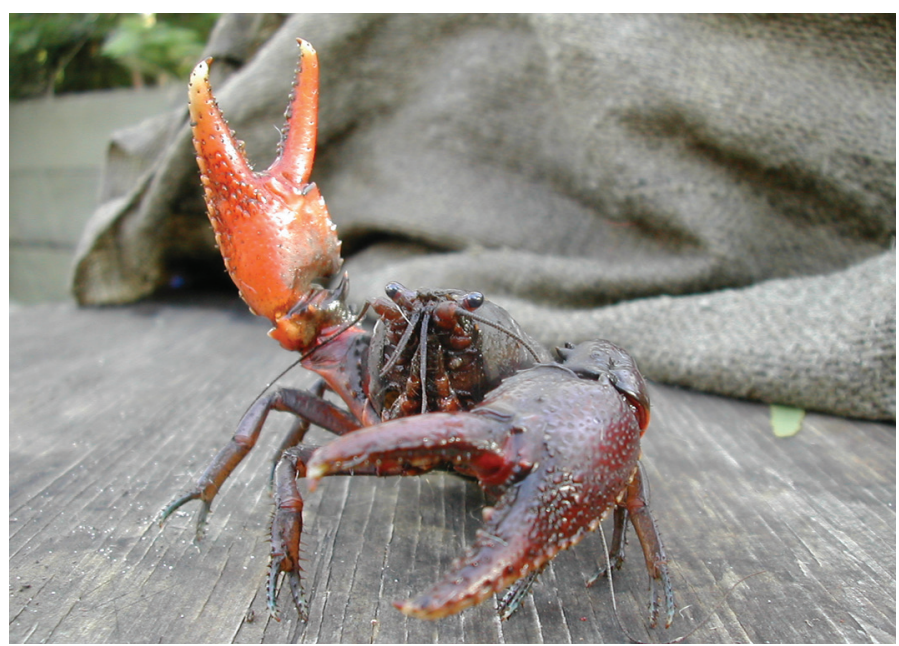

Figure I. The Blood Crayfish, Euastacus gumar (Morgan 1997). The species takes its name after the blood-red dorsal colouration of the claws. A vivid orange on the ventral surface is flashed in defensive poses.

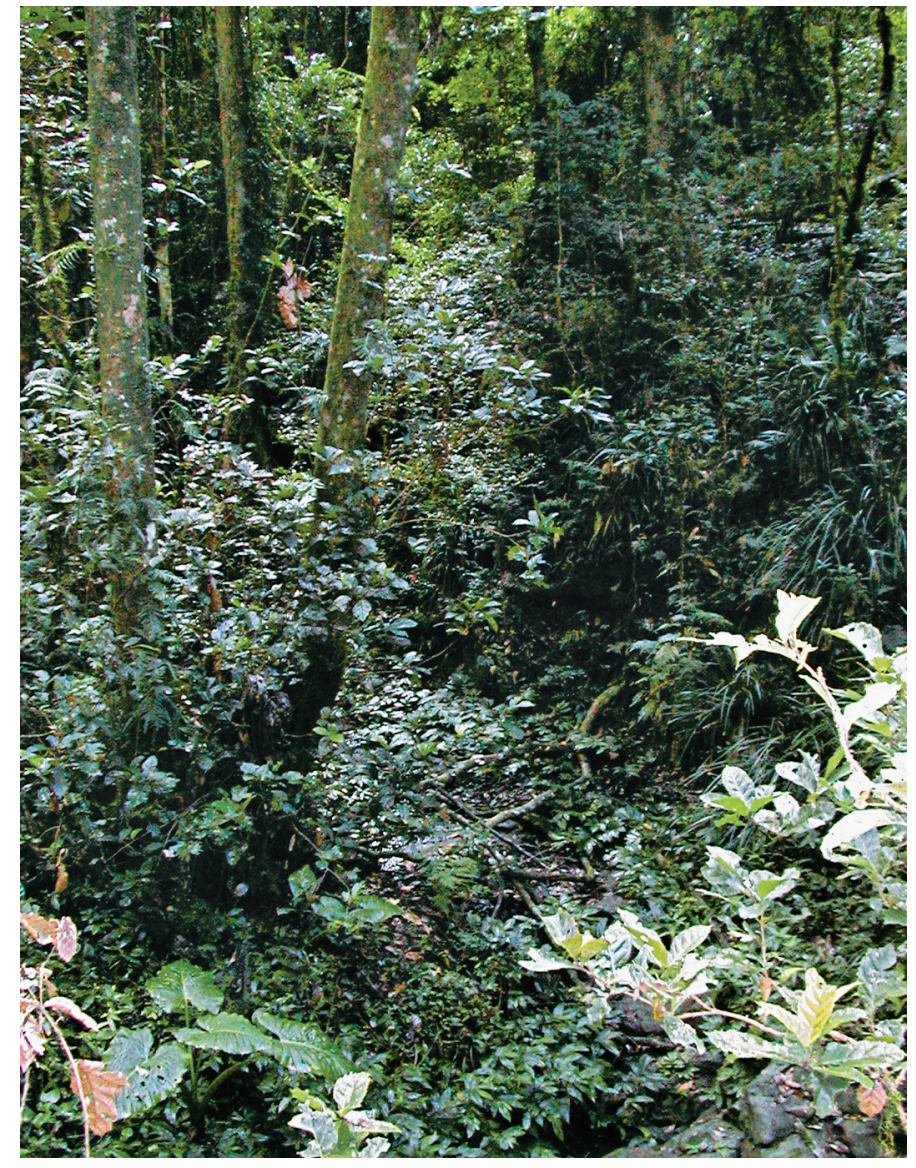

Figure I(i). the typical habitat of the species, in small rainforest gullies (in this case with negligible standing water present). 


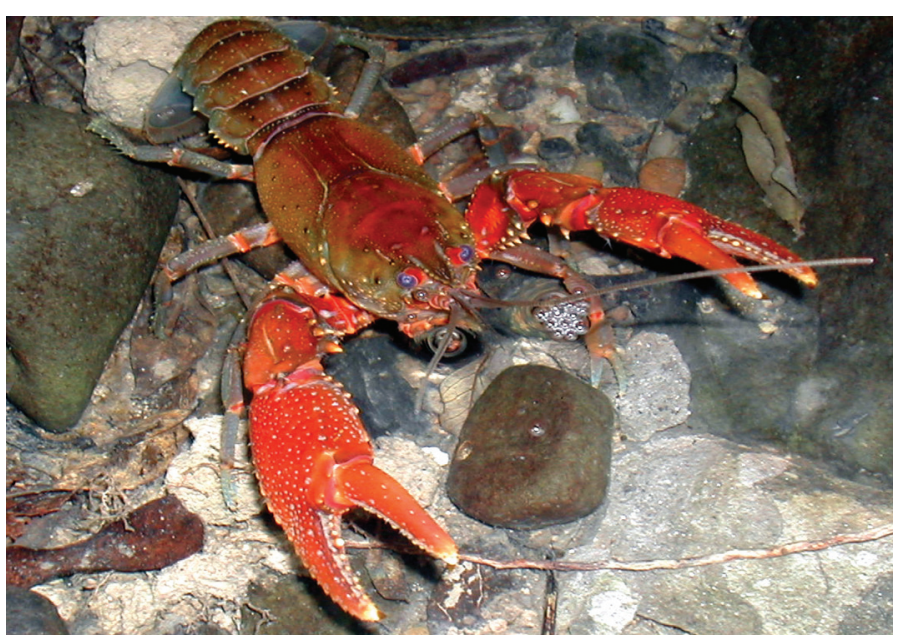

Figure I. (ii). dorsal colouration of a specimen in shallow water (illuminated with camera flash.
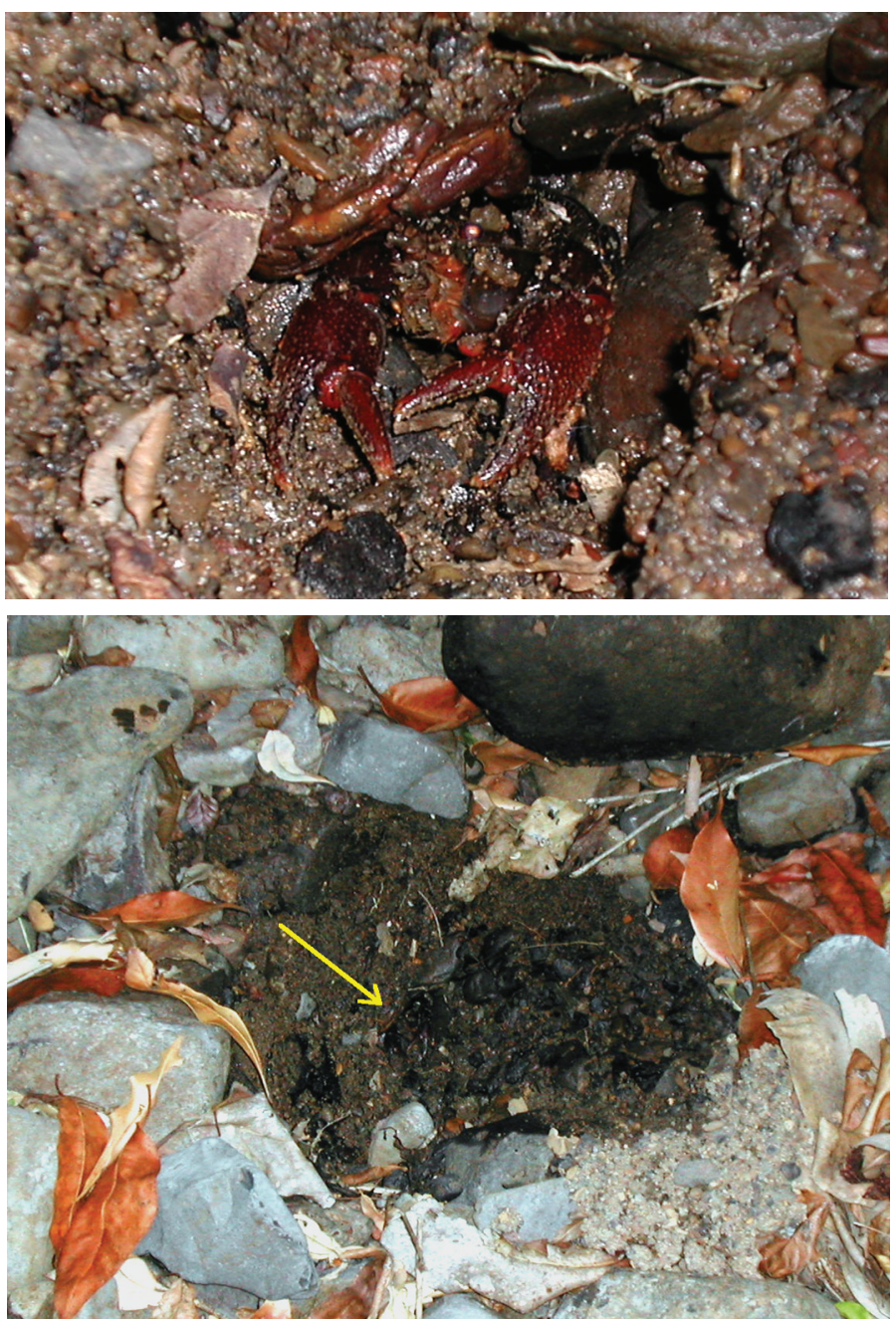

Figure I. (iii), (iv) an example of a shallow depression beneath a rock in moist substrate, unconnected to the water table or surface water.

a few kilometres from the cited collection locality, and it may be that the actual site lies within the Park itself rather than on the cattle station. Aside from its description, virtually nothing has been published on the species. The only information available on its biology is contained within the brief notes included with the description (Morgan 1997), and minor notes

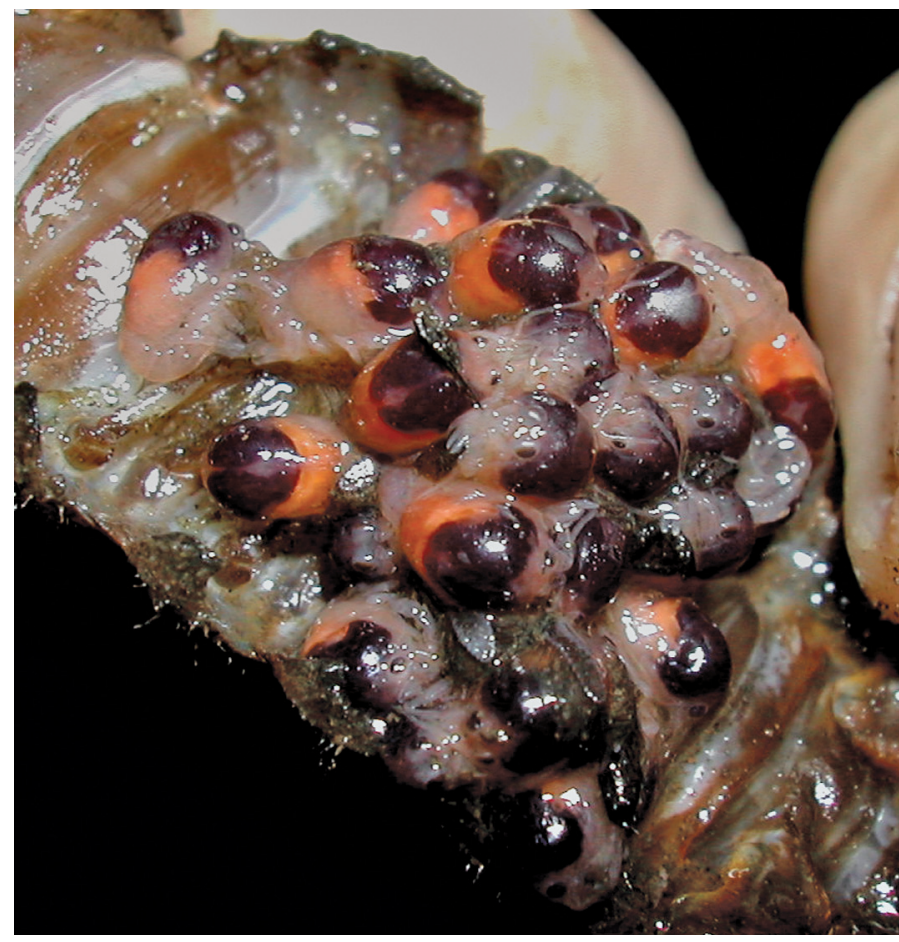

Figure I. (v) a typically small clutch of juveniles.

in regional field guides (Coughran 2006b; McCormack 2008). However, Australian crayfishes are increasingly being recognized as threatened, with as many as one third considered of conservation concern (Horwitz 1990, 1995). Consequently, it is imperative that poorly known species such as E. gumar receive research attention in order that their biology can be adequately understood and their conservation status determined. The aim of this paper is to determine the distribution and habitat requirements of Euastacus gumar, examine its basic biology (including population structure, behaviour, reproduction, growth and moulting), identify any real or potential threats to the species, and use this information to assess its conservation status.

\section{Methods}

\section{Distribution and habitat}

The distribution and habitat of the species was initially determined by sampling progressively from the type locality stream, concurrently recording micro- and macro-habitat information (Coughran 2000). Following that, a larger survey comprehensively sampled the entire northeastern New South Wales region (Coughran 2006a), and details on the distribution and habitat of the species was also collected in that survey. Habitat information recorded included the general and riparian vegetation classification, watercourse attributes, water quality $(\mathrm{pH}$, conductivity, dissolved oxygen, temperature), substratum and in-stream habitat, and surrounding land use. Where possible, bearings were recorded with a Garmin Venturer hand-held GPS, although due to poor satellite reception at some sites the bearings were estimated from the 1:25000 topographic map series (Land and Property Information NSW 2000), as were all site elevations. The National Parks and Wildlife Service's Frog Hygiene Protocol (NSW National Parks and Wildlife Service 2001) was followed throughout the study. 


\section{Long-term monitoring}

One site was chosen for a 24-month mark-recapture program. The long-term monitoring site was in upper Culmaran Creek, in the World Heritage-listed Cambridge Plateau (Richmond Range National Park). The entire length of Culmaran Creek above the falls $(\sim 2.3 \mathrm{~km})$ was navigated by foot, noting burrow density and the amount of substratum cover. The sampling site, being rather typical in these two regards, extends 100 $\mathrm{m}$ downstream from a point $20 \mathrm{~m}$ downstream of the main footbridge on the Culmaran Creek walking trail ( $\left.28^{\circ} 48.575^{\prime} \mathrm{S} 152^{\circ} 44.347^{\prime} \mathrm{E}\right)$. Culmaran Creek is a small, headwater stream with steep slopes on either side, in dry rainforest. During much of the sampling period, there was nil or negligible flow and many parts of the site held no surface water, although the substrate was moist. The substratum was fine and there was sparse (in pools) to high (in riffles) basalt cobble cover and moderate leafy debris throughout. Downstream of the site, closer to the falls, larger boulders become increasingly common. The site receives little sunlight, and aquatic plants are absent. Exposed rocks in the stream bed, however, are occasionally covered with terrestrial plants such as Rainforest Spinach, Elatostema reticulatum. Despite its small nature, upper Culmaran Creek was considered likely to hold higher densities of E. gumar than any other stream. The site was sampled each month for a period of 24 months, from August 2001 to July 2003. A site below the falls, in lower Culmaran Creek, was also sampled repeatedly at the outset of the long-term monitoring period, but proved to be unsuitable due to excessive dry conditions and difficulty in capturing animals.

\section{Collection and marking}

Crayfish were collected by either baiting in traps or by collection by hand from beneath rocks and logs. A small number of 'habitat traps', consisting of bundles of different diameter poly pipe weighed down in the stream bed, were installed at the long-term monitoring site in order to facilitate the collection of juveniles. Animals that were to be marked for recapture purposes were given a unique identifier by means of a tailfan clipping code (Figure 2) using a pair of thread cutters. This code allowed up to 199 specimens to be uniquely marked at the monitoring site, although only 154 animals were marked over the period. Some animals with such tailfan damage that confusion would have resulted had they been marked, or with such damage that marking was not possible, were excluded from marking. A small number of berried females, being rather aggressively protective of the clutch, were not marked so as to avoid disturbing the clutch. Generally, however, berried females were able to be marked. After marking and recording data (see below), crayfish were returned to the water at the point of capture. Animals retained for reproductive or taxonomic studies were returned to Southern Cross University in moist hessian sacks or cooled plastic containers containing some natural vegetation or leafy debris and a small amount of water. Specimens retained for taxonomic studies were vouchered and lodged with the Southern Cross University Collection, Lismore. Voucher specimens were euthanased by freezing prior to storage in 70\% ethanol, either directly or after fixation in a $10 \%$ neutral buffered formalin solution for two weeks.
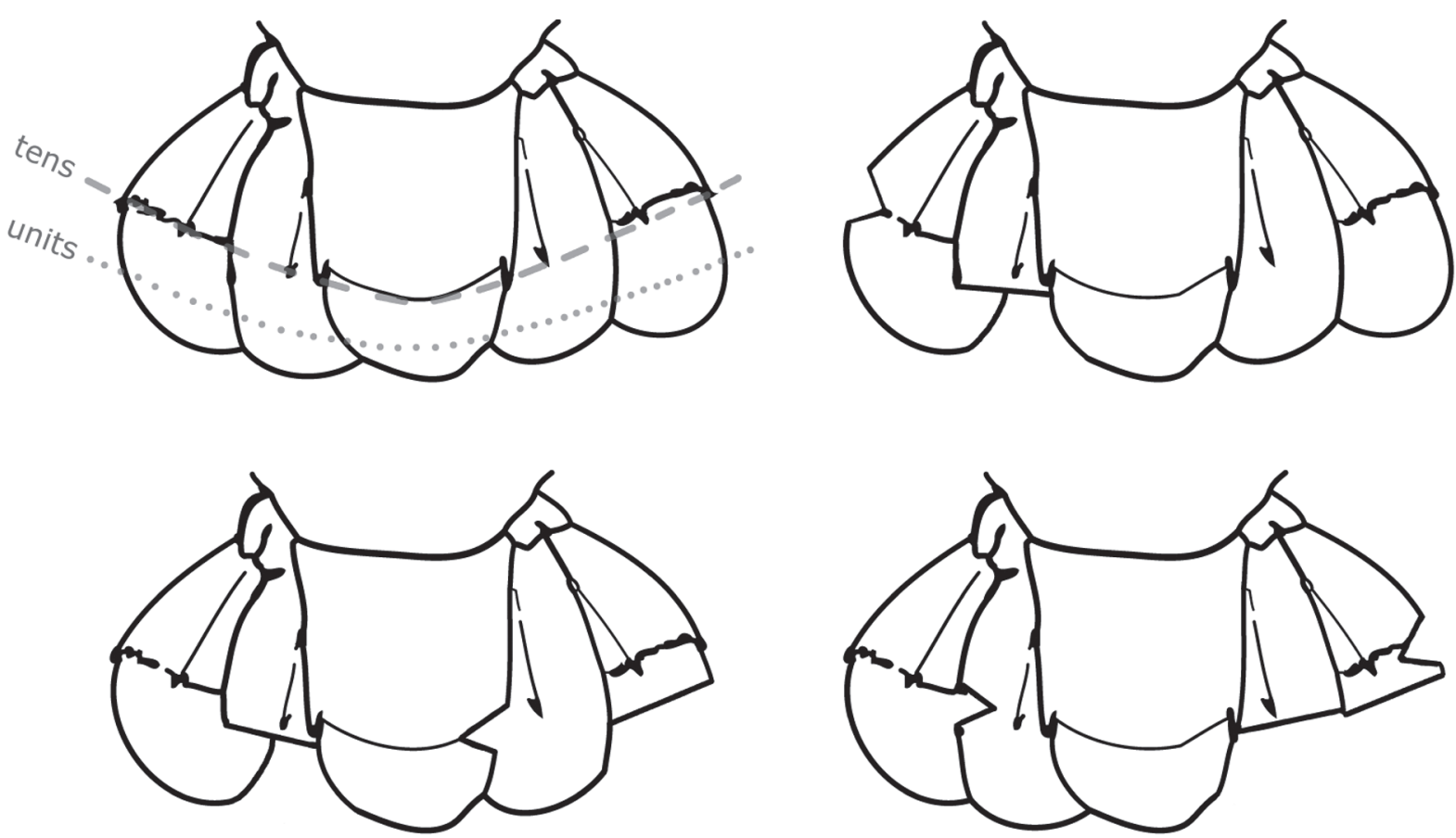

Figure 2. Illustration of the tailfan clipping code used to individually mark crayfish. The top left illustration depicts the lines along which tens were marked (with a lateral V-notch) and units (with a flat cut). Tens were marked on either side of the uropods and telson, from left to right across the tailfan, dorsally. Units were marked on the posterior margin of the uropods and telson, from left to right across the tailfan, dorsally. The remaining illustrations depict examples of marks for: 12 (top right); 67 (lower left); and 139 (lower right). 


\section{Density estimates}

Mark-recapture data from the long-term monitoring site were used to derive density estimates according to the Schumaker and Schnabel methods (see Schnabel 1938; Chapman 1952; Ricker 1975). Nets were installed at the up - and downstream ends of the stream stretch, in order to restrict migration of animals over the recapture period. Animals that were captured more than once during any monthly capture session (or period) were considered once only in the population estimates. Juveniles $<15$ $\mathrm{mm}$ OCL and injured animals were excluded from the density analyses. The long recapture period (around two years) is a compromise between two sources of error in population assessments, decreasing the chance of error due to natural fluctuations in the population (e.g. seasonal variation in catchability), but increasing the chance of error through other factors (e.g. mortality and recruitment). It is likely that the magnitude of errors incurred through mortality and recruitment was relatively low for this species, because of their slow growth rates and apparently long life spans. Restriction of the population estimates to animals $>15 \mathrm{~mm}$ OCL, and at a site within a protected area, may have also minimized any errors due to recruitment and mortality. Ricker (1975) noted that multiple census estimates are useful even when the conditions of no mortality and no recruitment are only approximately satisfied.

\section{Measurements and moult state}

In addition to marking (or checking for previous marks), measurements were made of occipital carapace length (OCL), a standard length measurement used in studies of Euastacus (Morey 1988, 1998; Lintermans and Rutzou 1991; Barker 1992; Honan and Mitchell 1995a; Turvey and Merrick 1997a; Borsboom 1998; Smith et al. 1998). Abdomen width (AbW) and propodal length (PropL) were also measured (see Morgan 1997). Very small animals and moulting animals were not marked or measured. Animals were also checked for: the presence or absence of temnocephalan flat worms; sex (including aberrant individuals); reproductive state; injuries and wounds; missing or regenerate pereiopods; softness of carapace (i.e. recently moulted or approaching moult); and the overall cleanliness of the ventral body surface. This last state was used as an approximate indicator of moult stage, in that animals with very dirty or discoloured undersides were considered to have moulted less recently than animals with very clean, white undersides (see also Hamr and Richardson 1994; Lappalainen and Pursiainen 1995, citing Appelberg and Odelström 1985).

\section{Long-term growth measurements}

Growth was examined in the field during the markrecapture study according to pre- and post-moult carapace measurements. The increase in OCL was used to derive a Percent Moult Increment (PCMI) (Hamr and Richardson 1994; Guan and Wiles 1996; Hamr 1997; Borsboom 1998), and index of growth expressed as the post-moult OCL by the pre-moult OCL.

\section{Reproductive studies}

All females were examined for signs of maturity essentially following other studies on Euastacus (e.g. Morgan 1986; Honan and Mitchell 1995c). Females were assigned to maturity states as their gonopores progressed from calcified and lacking setal development (immature) to membraneous and setose (mature). Females with intermediate signs of development (e.g. gonopores still calcified but with an incised rim) were classed as adolescent. The fecundity was roughly estimated for each female bearing a clutch of eggs or juveniles throughout the study, and a small number of berried females were retained for reproductive studies in laboratory aquaria at Southern Cross University. These aquaria were furnished with sand and gravel substrates, and leaf litter from the field site was added as a food source and to provide habitat. Crayfish were provided supplementary food as required, and aeration and water quality were maintained. During the study, these captive berried females were removed 2-3 times per week so that the clutch and individual eggs could be photographed. Individual eggs were carefully removed and photographed under a dissecting microscope, and details of the embryonic development recorded. Hatched juveniles were also monitored, and the timing of moults and independence from the mother was recorded.

\section{Results.}

\section{Distribution and habitat}

Euastacus gumar was recorded from 12 sites (Figure 3). A crayfish sighted at another site (in Peacock Creek) was also considered to be E. gumar, but the specimen eluded capture and no positive identification could be made. Small juveniles collected at a further site (in Gorge Creek) were also suspected to be E. gumar, but could not be positively identified due to their small size. Only two previous sites for the species have been published (Morgan 1997), in Gorge and Culmaran Creeks. The new sites presented here considerably extend the known distribution of the species south along the Richmond Range into Cherry Tree and Mt Belmore State Forests, and westward along the Yabbra Spur in Yabbra National Park. It is also of note that the southern populations (south of the Bruxner Highway) are situated east of the Richmond Range, constituting the only records of the species in the Richmond River drainage.

In Yabbra National Park, the species was recorded in close proximity to the Mountain Crayfish, E. sulcatus, although the two species were never recorded at the same site. At some sites the species overlaps with a lowland species of crayfish, the Cusped Crayfish Cherax cuspidatus (Coughran et al. 2008). All sites inhabited were in rainforest, or sclerophyll forest with gallery rainforest along the stream, in National Parks and State Forests. The substratum varied from clay to sand, with the species being notably more abundant in clayey environments. The species commonly digs depressions and burrows under rocks or woody debris, and to a lesser extent also burrows directly into the stream bed 


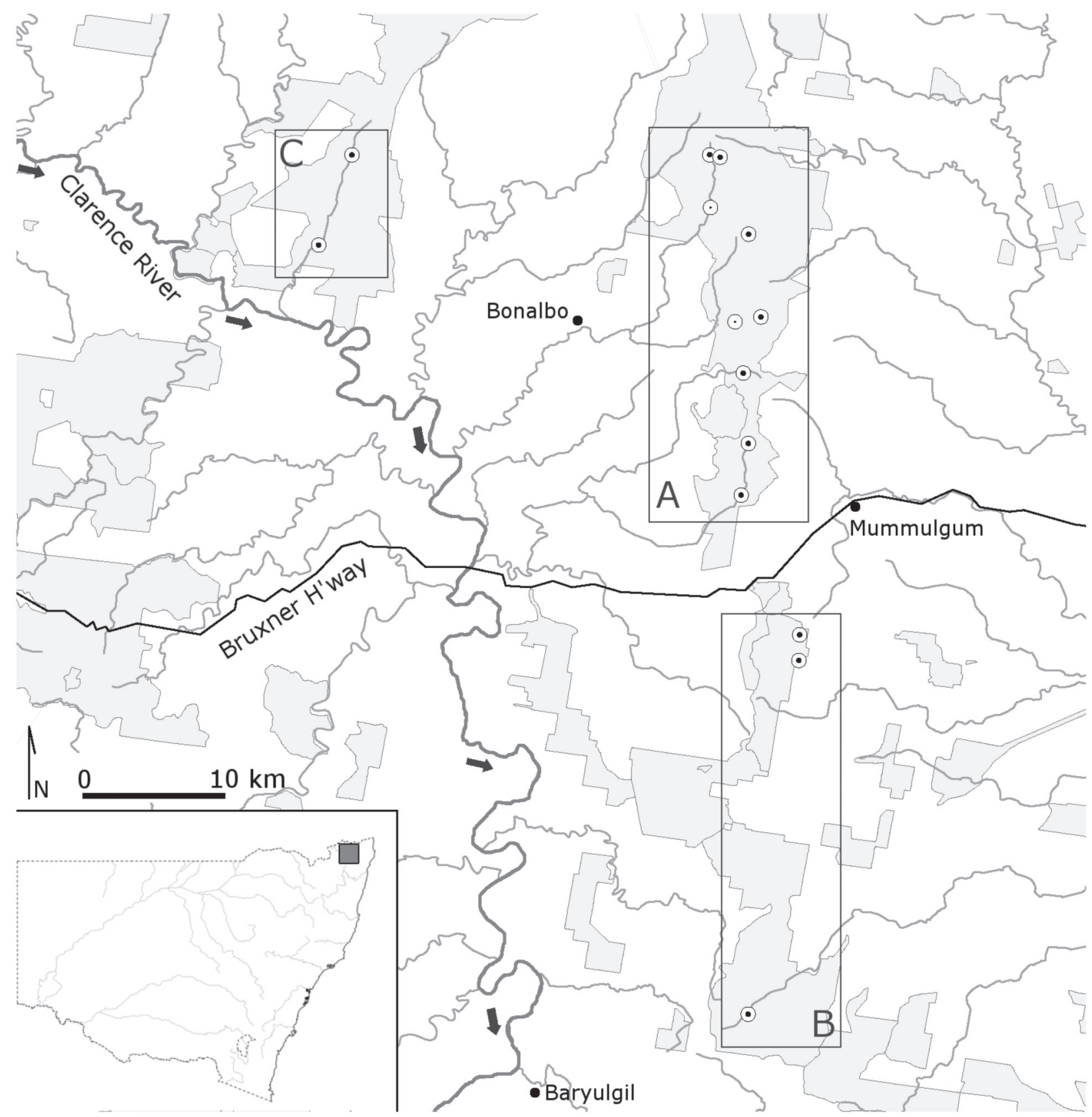

Figure 3. Distribution of Euastacus gumar. The icons with large black centres indicate the 12 sites at which the species was recorded, and those with small black centres indicate two further sites at which the species was suspected but not positively identified. The boxes refer to three distinct areas within the species' overall distribution: A) central Richmond Range (Clarence drainage); B) southern Richmond Range (Richmond drainage); and C) Yabbra Spur (western Clarence drainage). Areas shaded grey indicate state forest or national park lands.

and banks. Burrows associated with rocks or debris are often single-chambered or simple depressions, those not associated with rocks or debris and those in the stream banks are usually multi-chambered. Burrow entrances occasionally extend onto the forest floor immediately adjacent to the stream banks. The species is easily caught from under rocks and debris in the stream bed, tending to sit very still when exposed. The species does not readily respond to baits, however, and apart from a few reasonably successful trapping events this capture technique was found to be generally unproductive for the effort required. Visual census surveys (whether diurnal or nocturnal) are of limited use as the species appears to be highly dependent on its burrows, and animals do not readily venture from their burrow. The species was caught at several sites that held no surface water, and in some cases animals were collected from burrows under rocks that did not extend down to the water table. In one such case, a mature male and a female carrying a clutch of fresh eggs were caught under a large rock in a depression with no apparent access to water. Of the sites that did hold water, the $\mathrm{pH}$ ranged from 5.57 to 7.65 , the conductivity was low $\left(147-440 \mu \mathrm{s} . \mathrm{cm}^{-1}\right)$ and the dissolved oxygen was often

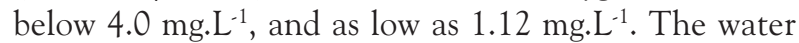
temperature of the habitats ranged from $11^{\circ} \mathrm{C}$ to $30^{\circ} \mathrm{C}$. 


\section{General population information}

In all, 327 animals (including recaptured animals) were measured and examined at upper Culmaran Creek. Fiftysix E. gumar individuals were measured and examined in the field from other sites in the broad distribution studies, providing a cumulative total of 383 animals. The average size recorded was $24.2 \mathrm{~mm}$ OCL, with a maximum of $44.1 \mathrm{~mm}$ OCL, well exceeding the previous maximum recorded size (37.2 mm OCL; Morgan 1997). The smallest free-living E. gumar caught had an OCL of $7.9 \mathrm{~mm}$, and was caught in a poly-pipe habitat trap. The smallest animal caught in a baited trap was 18.9 $\mathrm{mm}$ OCL. The overall male:female sex ratio of the longterm monitoring program (excluding recaptures and specimens $<15 \mathrm{~mm} \mathrm{OCL})$ was $1: 1.06(\mathrm{n}=251)$, and was not significantly different to a $1: 1$ ratio $\left(x^{2}<2.06 ; d f=\right.$ $1 ; \mathrm{p}>0.1)$. Although they need to be interpreted with some caution given the inherent non-randomness of the only suitable sampling technique for this species (i.e., burrow excavation or lifting rocks), the density estimates ranged from 5.23-5.37 crayfish per linear metre of stream length, depending on the method of calculation applied.

Eighteen animals measured and examined in the field sacrificed a cheliped during handling. Excluding these, $56.1 \%$ of animals bore two normal (non-regenerate; $<1$ $\mathrm{mm}$ difference) chelipeds. Other animals were either missing a cheliped or bore soft chela buds $(11 \%)$, or had a regenerate $(15.3 \%)$ or slightly regenerate (15.3\%) cheliped. Some animals had both chelae in some regenerative state (absent, bud, regenerate or slightly regenerate). Wounds were recorded on $33.0 \%$ of specimens from the long-term monitoring site in Culmaran Creek. Apart from missing or damaged pereiopods (28.3\%), wounds were most commonly recorded in the tailfan (2.5\%). A few animals had wounds on the abdomen or thorax, and one animal had a broken rostrum. One animal had burn spot disease on the carapace. Euastacus gumar commonly hosts a small, unpigmented temnocephalan flatworm, and most populations also hosted a large, pigmented temnocephalan species. However, the pigmented species was not recorded from upper Culmaran Creek, despite being commonly recorded from the population below the falls (in lower Culmaran Creek). Seasonal variation in temperature or rainfall have been found to affect temnocephalan numbers (Cannon and Jennings 1987; Jones and Lester 1993), but it is unlikely that this could explain the absence of the pigmented worms from the upper Culmaran Creek population; more than 300 crayfish were examined from upper Culmaran Creek, and it would be expected that if the population hosted the pigmented temnocephalans, at least one worm would have been recorded during the 24-month monitoring period.

\section{Growth and moulting}

Thirty-three $(21.4 \%)$ of the marked animals were recaptured at least once during the study, and ten animals were recaptured at least twice or more (up to a maximum of six recaptures). The mean monthly recapture rate over the 24 month period was $16 \%$. Marks were easily recognisable even after moulting due to a distinct warping of the regrowing integument. Throughout the study, nine animals were caught that bore damaged tailfans that resembled marks, yet upon cross-reference with records did not match any of the originally marked animals. These unmarked animals were examined and measured, but excluded from analyses involving recapture data.

In animals $>15 \mathrm{~mm}$ OCL, growth appears to coincide with the warmer months, and all recent moults were recorded from September to April (Figure 4). Further, there were only two records of animals $\leq 15 \mathrm{~mm}$ OCL moulting outside this season: a single record of a freshly moulted animal in July and again in August. A high proportion of animals were recorded with a 'dirty' exoskeleton condition factor throughout the year (generally 40-80\%, higher in January for which $<10$ animals were recorded).

Thirteen of the 33 recaptured E. gumar had moulted between captures, and estimates of the number of moults could be made for 12 of these 13 animals (Table 1). There was only low incidence of growth in recaptured animals, and it appears that growth increments are not necessarily correlated with age/size. For example, a 28.5 $\mathrm{mm}$ OCL male had a higher PCMI (for OCL) than several smaller males, including one male $<20 \mathrm{~mm}$ OCL. Again, a female of $23.4 \mathrm{~mm}$ OCL had a higher PCMI (for OCL) than two females $18.6 \mathrm{~mm}$ and 18.9 $\mathrm{mm}$ OCL. Conversely, some animals near $24 \mathrm{~mm}$ OCL had a slightly higher PCMI (for OCL) than animals over $30 \mathrm{~mm}$ OCL. Two E. gumar individuals that had previously lost chelae and were bearing soft, regenerative chela buds when marked, were found to have regrown their missing chelae to a considerable size $(65.4 \%$ and $66.2 \%$ of normal chelae) by the time of their recapture, almost certainly after only one moult. Another specimen with an already calcified regenerate chela when marked had a notably larger than normal increase in propodal length $(28.3 \%)$ yet had an increase in OCL comparable to the mean $(5.6 \%)$. Other animals with only slightly regenerate chelae (i.e. almost regrown) when marked did not show any disproportionate increase in propodal length upon recapture. These findings suggest that after the initial loss of a cheliped, E. gumar expend much energy regrowing it at the next two moults and return to a more balanced, overall growth in subsequent moults. Consequently, a limb could essentially be regrown two moult events after its sacrifice.

\section{Reproduction}

\section{Size at female maturity}

The size of females at sexual maturity varied across a considerable range. The smallest female with mature gonopore characteristics was $22.9 \mathrm{~mm}$ OCL. However, several females $>30 \mathrm{~mm}$ OCL had immature or adolescent gonopore characteristics. The number of females with mature gonopores at various size classes is shown in Figure 5. The mean AbW/OCL ratio for mature, female E. gumar was $0.56(\mathrm{n}=29)$, and 0.53 for both immature $(n=64)$ and adolescent $(n=19)$ animals. 


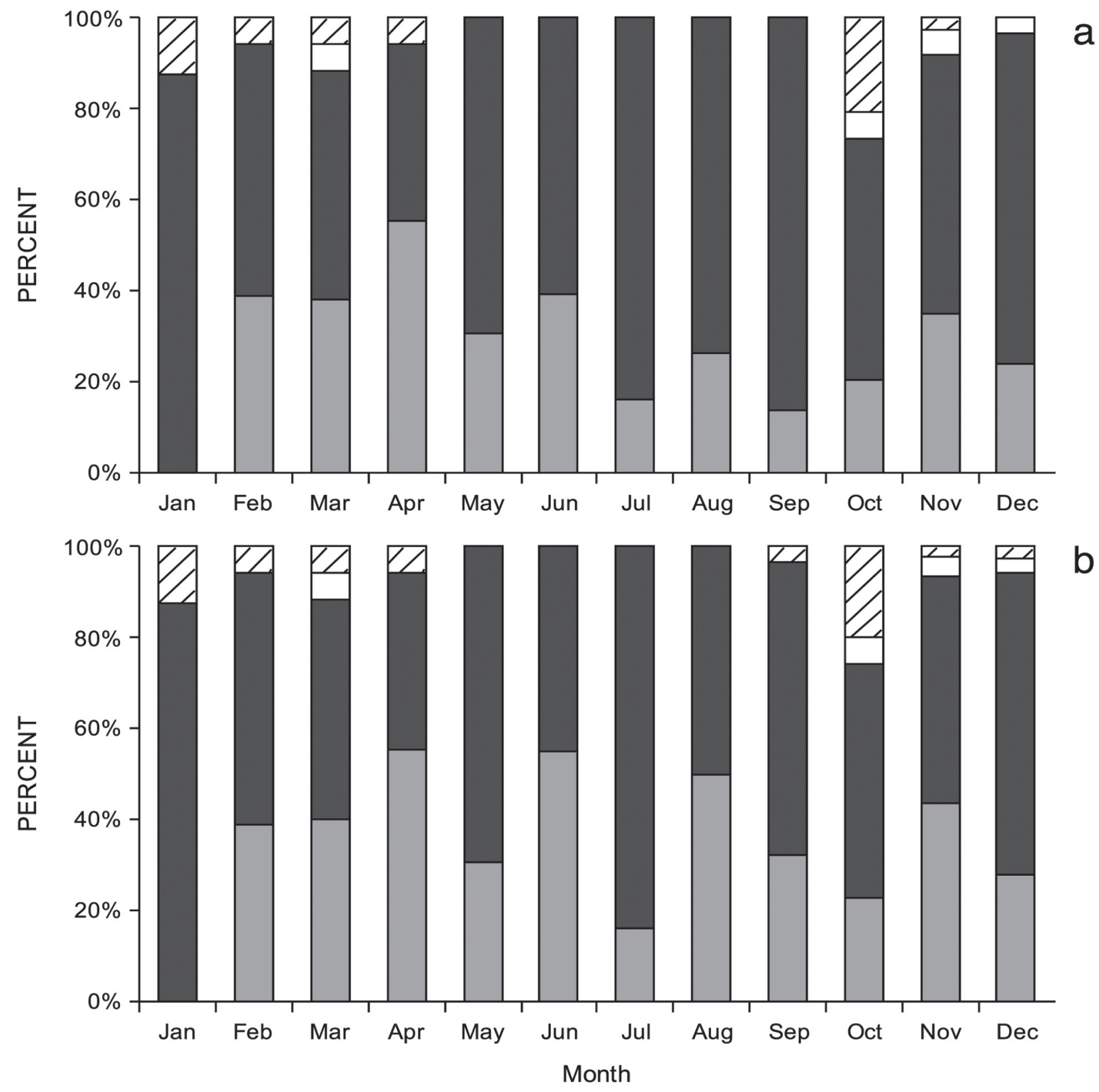

Figure 4. Exoskeleton condition factor for Euastacus gumar, by month of capture, for: a) upper Culmaran Ck ( $n=3 \mid 5)$; and $b$ ) all sites of record pooled $(n=369)$. Exoskeleton condition factor is indicated as follows: (i) grey - hard and clean; (ii) black - hard and dirty; (iii) white - very soft (fresh moult); (iv) hatched - semi-soft (recent moult). Data are restricted to animals > $15 \mathrm{~mm} O C L$.

\section{Sexual dimorphism}

Sexual dimorphism was evident in animals $>25 \mathrm{~mm}$ OCL, and takes the form of a proportionally larger propodal length (i.e. larger chelae) in males $(\mathrm{p}<0.05)$, and a broader abdomen in females $(\mathrm{p}<0.0001)$.

\section{Aberrant sexual characters}

Aberrant sexual characters were recorded in only four animals $(\sim 1 \%$ of the population). All four aberrant animals bore both male gonopores on the fifth pair of pereiopods (the correct male position). One of the animals also bore both female gonopores on the third pair of pereiopods (the correct female position). The other three animals bore a single female gonopore on the third pereiopod on one side only.

\section{Reproductive activity}

Twelve Euastacus gumar females were carrying eggs or young when captured (including one voucher specimen - KCK.Gd.32 - eggs preserved with mother). The size of egg-bearing females ranged from 29.2-42.3 mm OCL and fecundity ranged from 20-150 eggs per clutch. Three of the females had a regenerate cheliped, and a fourth was missing one cheliped. With these exceptions, the 12 females were in 'good' condition, with no wounds or injuries noted. Although some reproductively active females had a 'clean' exoskeleton condition, several had a 'dirty' exoskeleton condition, suggesting that females do not routinely moult prior to spawning. Five of the reproductively active females carried temnocephalan flatworms. The timing of reproductive activity for the 12 
Table I. Growth and moulting records for recaptured Euastacus gumar, from upper Culmaran Ck, and determination of the Percent Moult Incremental Increase (PCMI) and Absolute Growth Rate (AbGR), for carapace length $(\mathrm{OCL})$. C»>R, earliest and latest months of capture and recapture for each growth interval; $t_{m^{\prime}}$, time in months between capture records; Est. M, estimated moults between records; Pre, measurement prior to moulting (mm); Post, measurement after moulting (mm); $\mathrm{MI}$, moult increment $(\mathrm{mm})$. Mean values are used for $\mathrm{MI}$ and PCMI for animals it was estimated had moulted twice. Two growth records are entered separately for one male animal which was recaptured twice and had moulted each time. Given the uncertainty over the number of estimated moults for one of the female animals [in square brackets], it was excluded from considerations in further growth estimates. PCMI data were also recorded for propodal length and abdomen width, for brevity not presented here.

\begin{tabular}{|c|c|c|c|c|c|c|c|}
\hline & $C » R$ & $t_{m}$ & Est. M & Pre $(\mathrm{mm})$ & Post (mm) & $\mathrm{MI}(\mathrm{mm})$ & PCMI (\%) \\
\hline \multirow{4}{*}{ 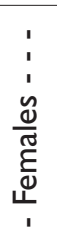 } & Apr-Jun & 2 & I & 18.6 & 19.8 & 1.2 & 6.5 \\
\hline & Aug-Nov & 3 & I & 18.9 & 20.4 & 1.5 & 7.9 \\
\hline & Dec-Apr & 4 & I & 32.1 & 32.9 & 0.8 & 2.5 \\
\hline & May-Feb & 9 & $1 \sim 2$ & 20.8 & 23.6 & 2.8 & {$[13.5]$} \\
\hline \multirow[t]{3}{*}{ ! } & Apr-Feb & 10 & 2 & 23.4 & 28.0 & 2.3 & 9.8 \\
\hline & Mean Female PCMI & & & & & & 8.1 \\
\hline & Oct-Nov & I & I & 33.7 & 35.0 & 1.3 & 3.9 \\
\hline \multirow{5}{*}{$\begin{array}{c}1 \\
\vdots \\
\vdots \\
\frac{\tilde{d}}{\pi} \\
\sum_{1}^{\pi}\end{array}$} & Aug-Nov & 3 & I & 19.6 & 21.0 & 1.4 & 7.1 \\
\hline & Nov-Mar & 4 & I & 19.8 & 21.1 & 1.3 & 6.6 \\
\hline & Oct-Feb & 4 & I & 28.5 & 30.5 & 2.0 & 7.0 \\
\hline & Aug-Mar & 7 & I & 24.2 & 25.5 & 1.3 & 5.4 \\
\hline & Sep-Jul & 10 & I & 24.0 & 25.0 & 1.0 & 4.2 \\
\hline \multirow{3}{*}{$\begin{array}{l}: \\
: \\
:\end{array}$} & May-Mar & 10 & I & 27.1 & 28.5 & 1.4 & 5.2 \\
\hline & Sep-Oct & 13 & 2 & 23.2 & 25.5 & 1.2 & 5.2 \\
\hline & Jun-Oct & 16 & 2 & 31.5 & 33.7 & 1.1 & 3.5 \\
\hline & Mean Male PCMI & & & & & & 5.6 \\
\hline & Mean Overall PCMI & & & & & & 6.4 \\
\hline
\end{tabular}

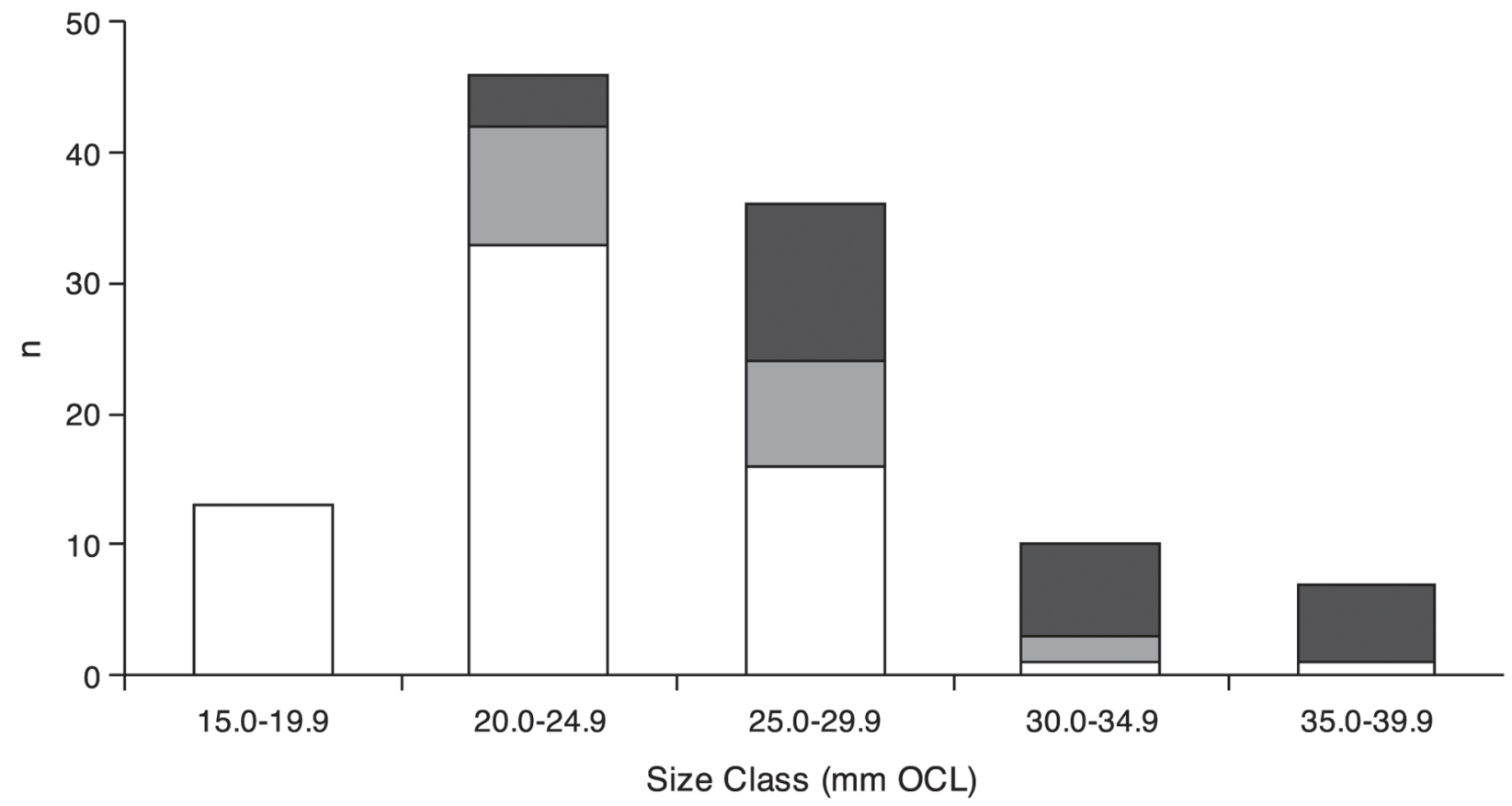

Figure 5. Size at female maturity for Euastacus gumar. Based on gonopore states, females were classed as either immature (white), adolescent (grey), or mature (black). Data are presented for the long-term monitoring sites only. 
E. gumar females is shown in Figure 6. The comparatively few data suggest that E. gumar is a winter-spring brooder, with juveniles being released in summer. Fewer than half of the females larger than the minimum size at egg bearing that were captured during the reproductive season were carrying eggs or young.

\section{Egg and juvenile development}

Due to the low incidence of reproductive activity and the small clutch size of this relatively uncommon species, egg measurements are based on a small sample of 36 eggs taken from four females. The mean egg width was 2.68 $\mathrm{mm}$ (a mean of $9 \%$ of OCL), and the mean egg length was $3.39 \mathrm{~mm}$ (a mean of 12\% of OCL). Freshly-laid eggs are olive or greenish grey in colour. The developing yolk turns a dark purple-grey or black, with a lighter, pinkish tinge immediately adjacent to the embryo. The eggs hatched between 49 and 56 days after capture. New hatchlings bear an undeveloped tailfan, larval cephalothorax, telson thread and the recurved terminal hook and spine arrangement on the $4^{\text {th }}$ and $5^{\text {th }}$ pairs of pereiopods, features that are characteristic of other parastacid hatchlings (Clark 1936, 1937; Shipway 1951; Hopkins 1967; Suter 1977; Hamr 1992; Honan 1998). Juveniles pass through two moults (i.e. three intermoult stages) prior to independence. When pigmented, juveniles have very distinctive cream bands across the first and last abdominal segments.

Juveniles became independent around three weeks after hatch, and underwent their first independent moult two weeks after leaving the mother. The OCL after the first independent moult was 4.5-5.0 mm. After a further two weeks several had moulted to around $6.0 \mathrm{~mm}$ OCL, and by seven weeks independence a third moult to around $8.0 \mathrm{~mm}$ OCL was recorded for some individuals. At nine weeks independence, a few animals underwent their fourth independent moult to around $9.0 \mathrm{~mm} \mathrm{OCL}$, and by 12 weeks independence (i.e. 150 days after eggs were laid) no crayfish had moulted further. The egg and juvenile development for E. gumar (and other species), with accompanying photographs, is described more completely elsewhere (Coughran 2006a).

\section{Discussion}

\section{Distribution and habitat}

Euastacus gumar can be considered a highland species, as it only inhabits the headwaters of the streams it occurs in. However, it is worth noting that at one site the elevation is below $200 \mathrm{~m}$ (a defining elevation previously applied to generally separate highland from lowland species; Morgan 1997), a reflection of the local topography. Although its upland, rainforested distribution may reflect a requirement for cool conditions, the species does not require clear, flowing, oxygenated water, as has been noted for the genus generally (e.g. Riek 1969; Johnson 1982; Horwitz 1990; Merrick 1993; Morgan 1997). Animals were collected from sites with and without surface water, and in some cases the burrows extended down into moist clay, but were unconnected to the water table. When present, surface water was often of very low dissolved oxygen content. The collection of a berried female from a burrow system unconnected to permanent water is a most interesting record. It is difficult to imagine how a clutch of eggs, and then young, could be successfully carried through such conditions given the length of time required for development.

\section{Reproductive biology}

Although previous studies have found that Euastacus spp. carry eggs and juveniles for long periods in excess of four months (Honan and Mitchell 1995c; Turvey and Merrick 1997a), the entire reproductive development for E. gumar was complete in just over two months. Despite the substantially different egg sizes, the development period for E. gumar was comparable to that for Cherax cuspidatus (Coughran 2006a). However, egg and juvenile development may have progressed faster in the laboratory than in the field, and more intensive studies in field situations would be of use in refining this estimate. Nonetheless, the development in E. gumar progressed faster than for other species of Euastacus monitored in the laboratory during the same study (Coughran 2006a). The fecundity is also notably low (20-150 eggs) compared to several considerably larger species in the genus, some

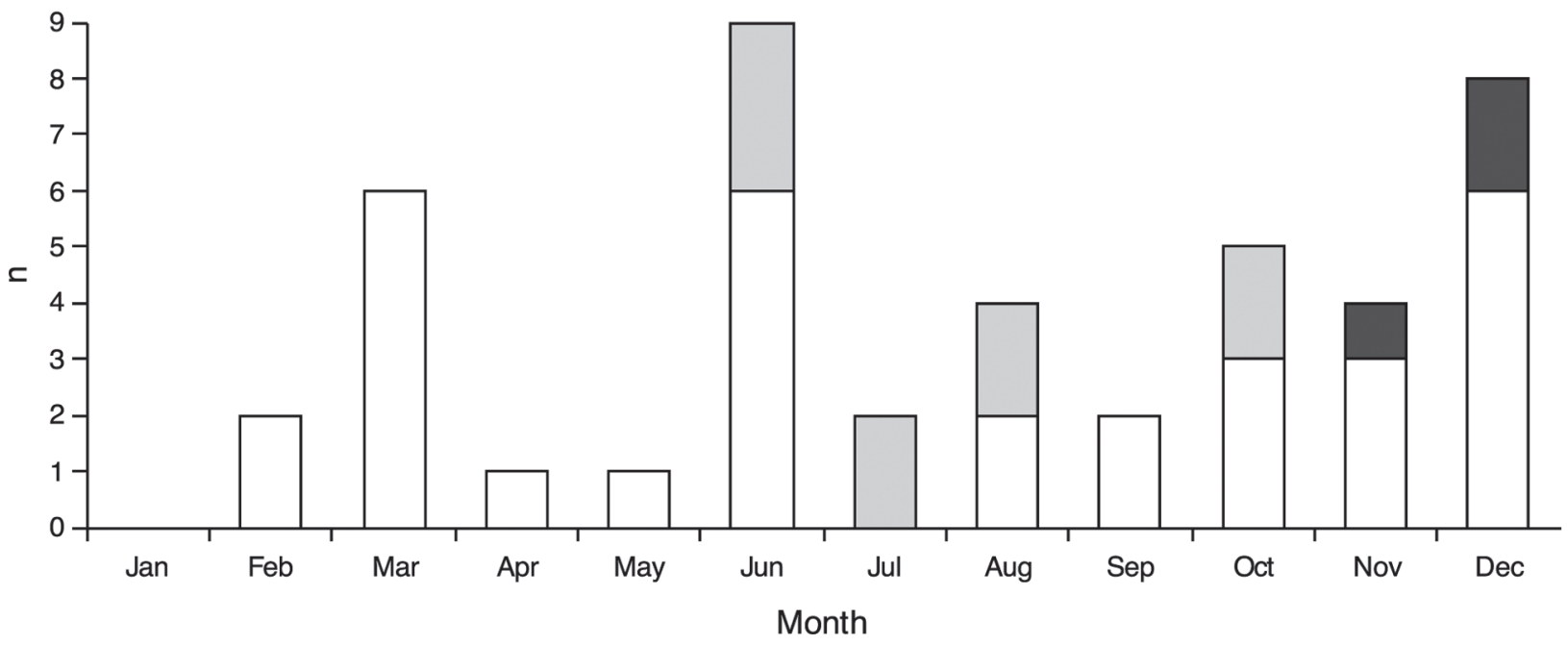

Figure 6. Reproductive activity for Euastacus gumar females of at least the minimum size at egg bearing $(29.2 \mathrm{~mm} \bigcirc \mathrm{CL})$. Pooled monthly data are presented for females: (i) without eggs or juveniles (white); (ii) carrying eggs (grey), and; (iii) carrying juveniles (black), when captured. 
of which bear several hundred to over 1000 eggs (Clark 1937; Honan and Mitchell 1995c; Turvey and Merrick 1997a; Morey 1998; Coughran 2006a). The fecundity in E. gumar is more similar to that recorded for similarly small Euastacus spp. (Morgan 1997; Borsboom 1998; author, unpublished data), and other small species such as Cherax quinquecarinatus (Beatty et al. 2005).

\section{Growth rates and longevity}

Euastacus gumar is a slow-growing species, and likely longlived species, consistent with other studies of this genus (Anon. 1988; Hutchings 1988; Honan and Mitchell 1995b; Morey and Hollis 1997; Turvey and Merrick 1997c; Barnham 1998; Borsboom 1998; Morey 1998). Crayfish growth is a factor of both the moult increment and the intermoult period (Hartnoll 1983). Although both could account for the low growth observed in the present study, the intermoult period appears to be the most important factor. The size and range of moult increments recorded for E. gumar are comparable to studies on other Euastacus spp. (Honan and Mitchell 1995b; Turvey and Merrick 1997b; Borsboom 1998; Morey 1998; Furse and Wild 2004). Few recaptures were made for the species that involved growth over periods of more than 12 months, and most of the records are for relatively small animals, which moulted once or twice. Future studies should extend for longer than 2 years (preferably 5-10 years) to provide more information on the moult frequency and to refine growth rate estimates. Given the low abundance of the species, and the difficulty in catching sufficient quantities, such research should consider a more effective and enduring marking method. Any future research should take into account that moulting appears to occur primarily in the warmer months, in order to provide the best data return for effort. It is also worth pointing out that growth cannot be estimated using the size-frequency distribution method. Although the method is commonly used for crayfish (e.g. Hopkins 1966; Goldman and Rundquist 1977; Correia 1993; Borsboom 1998), the low abundance and apparent longevity of Euastacus gumar breaches two of the four tenets for this method of age estimation (France et al. 1991).

The low number of recaptured animals that had moulted since marking is insufficient to derive growth equations for these species and provide accurate longevity estimates. A wide range of age estimates have been observed for other Euastacus spp. (Turvey and Merrick 1997c), and the variation in moult increment observed in the present study would undoubtedly contribute to a similarly wide range of age estimates for E. gumar. The paucity of juvenile growth data also makes the approximation of age for these species difficult. Juveniles that survived in aquaria after the reproduction studies grew at widely varying rates and it is likely that juveniles in the wild also exhibit different growth rates. Animals at around $25 \mathrm{~mm}$ OCL could conceivably be between 1-5 years of age. The difficulty in predicting age from growth rate is highlighted by the example of one specimen taking 13 months, and two moults, to increase in OCL from 23.2-25.5mm. Studies on other Euastacus spp. have also indicated that at least 2-3 years would be required to attain $25 \mathrm{~mm}$ OCL (Borsboom
1998; Turvey and Merrick 1997c; Furse and Wild 2004). If this is so, then based on the observations of moult increment for animals of various sizes, it is reasonable to assume that many E. gumar animals at $30 \mathrm{~mm}$ OCL could be $5-10$ years old, and the largest specimens $(>40 \mathrm{~mm}$ OCL) considerably older.

The low moult frequency and thus slow growth rate of Euastacus spp. could be due to a number of extrinsic factors, such as temperature and food supply (Hartnoll 1983). For some species, threshold temperatures have been identified below which moulting will not occur, regardless of other factors (Momot 1984). For example, the European Austropotamobius pallipes will not moult at temperatures below $10^{\circ} \mathrm{C}$ (Pratten 1980). Whitmore and Huryn (1999) considered that, in addition to low temperatures, high competition for resources may contribute to the low growth of Paranephrops zealandicus. Furthermore, an increased incidence of mortality is often noted in association with moulting, due to factors such as predation, cannibalism, or unsuccessful moult events (e.g. Momot 1967; Brewis and Bowler 1983; Furse and Wild 2004). Moult-related mortality also might either directly limit the suitable moult periods for these Euastacus species, or adversely affect the capture and recapture data.

\section{Conservation status and future research}

The overall extent of occurrence (EOO) of the species is estimated to be $985 \mathrm{~km}^{2}$. However, the distribution consists of widely separated sites across three disjunct areas. If considered alone, the EOO of each of these three areas falls well below $100 \mathrm{~km}^{2}$ (central Richmond Range $\sim 39.5 \mathrm{~km}^{2}$; southern Richmond Range $<5 \mathrm{~km}^{2}$; Yabbra Spur $<2 \mathrm{~km}^{2}$ ), although these figures should be viewed with some caution given the low number of sites in the southern and western areas. Although there are no morphological grounds to distinguish populations within or between the three areas (Coughran and Leckie 2007), the generally perceived barriers to upland species of Euastacus (i.e., mountain ranges and uninhabited lowland country) appear to apply in the case of E. gumar, with the species being restricted to headwaters of different stream systems. There may also be population distinctions within each of these three areas. For example, the restriction of the species to headwaters would suggest a possible difference between catchments, and the escarpment along the Richmond Range may represent a barrier between populations in upper and lower Culmaran Creek. Further research into the population genetics of the species is warranted.

The species should be considered as 'Endangered' under IUCN criteria, based on its restricted (extent of occurrence $<1000 \mathrm{~km}^{2}$ ) and fragmented (three disjunct areas) distribution, and an anticipated decline in quality of habitat due to climate change [EN: B1+2(a),(b)iii]. Given its restricted and fragmented, upland distribution, any loss or decline of suitable habitat represents a potential threat to the species. Climate change represents a significant threat in this regard, through impacts on the amount and quality of habitat. The climate change scenarios for the region predict increased temperatures and altered hydrological regimes (Chiew and McMahon 2002; Howden 2003; Hennessy 2006), directly threatening this species. 
In addition, these climate change impacts will also result in a substantial regional decrease in the area occupied by rainforest vegetation (A. Specht, pers. comm. 2008, SCU), the required habitat for E. gumar. Laboratory research into the thermal tolerance of the species would therefore be beneficial, and if combined with intensive field monitoring of habitat conditions may enable modeling of the potential impacts of climate change on the species. The species may also be susceptible to impacts associated with the introduced Cane Toad Bufo marinus, and laboratory research should be initiated into the potential threat of this species. Management of forests and reserves should consider this crayfish and its habitat in management plans. In particular, the species is restricted to sites with at least gallery rainforest present along the streams, and such areas should be adequately protected.
The application of a common name may serve to highlight the diversity of crayfish in Australia (something largely unappreciated at present), and assist with awareness and recognition of this species in management considerations. No common name was applied in the original description by Morgan (1997), who selected the epithet 'gumar' (the Bundjalung aboriginal word for 'blood') after the colouration of the claws (specifically, the dorsal surface of the propodus). As such, I have nominated 'Blood Crayfish' as a suitable common name here. Other alternative names considered have a number of potential drawbacks, for example 'Bloodclaw' (this may be confusing with the introduced 'Redclaw'), or the 'Richmond Range Crayfish' (this may result in inadequate collection records in the future given that four other species of crayfish occur along the Richmond Range).

\section{Acknowledgements.}

Field work was undertaken during the author's postgraduate research at Southern Cross University, under the supervision of Don Gartside. Funding was provided by the School of Environmental Science and Management (SCU), the Australian Geographic Society and the New South Wales Fisheries Scientific Committee. Ben Black, Amy Coughran, Ted Hamilton, Gavin Hampton, Shawn Leckie, Benn Lovejoy, David Newell and Stephen Waddington assisted with field work. I thank Stephen King (NPWS) for providing information and maps to assist with site location. James Furse assisted with the assessment of conservation status. The manuscript was considerably improved thanks to the corrections and comments of James Fitzsimons, Bradley Law and an anonymous reviewer. Sampling was conducted under NSW Fisheries Scientific Collecting Permit no. P00/025. Finally, I must also thank the National Parks and Wildlife Service, State Forests of New South Wales, and various private landholders for granting research access.

\section{References.}

Anon. 1988. Many species, only a few with aquaculture potential. Austasia Aquaculture Magazine 2(9): 3.

Appelberg, M. and Odelström, T. 1985. Recommendationer för provfiske efter kräftor. Information från sötvattens, laboratoriet Drottningholm (7). 28 pp. (In Swedish).

Barker, J. 1992. The Spiny Freshwater Crayfish Monitoring Program. (Fisheries Management Report No. 44). Inland Fisheries Management Branch, Fisheries Management Division, Department of Conservation and Environment.

Barnham, C. 1998. Freshwater Fish of Victoria - Spiny Freshwater Crayfish. Fisheries Note Series (No. 78), Department of Natural Resources and Environment, Victoria.

Beatty, S.J., Morgan, D.L. and Gill, H.S. 2005. Life history and reproductive biology of the Gilgie, Cherax quinquecarinatus, a freshwater crayfish endemic to southwestern Australia. Journal of Crustacean Biology 25: 251-262.

Borsboom, A. 1998. Aspects of the biology and ecology of the Australian freshwater crayfish, Euastacus urospinosus (Decapoda: Parastacidae). Proceedings of the Linnean Society of New South Wales 119: 87-100.

Brewis, J.M. and Bowler, K. 1983. A study of the dynamics of a natural population of the freshwater crayfish, Austropotamobius pallipes. Freshwater Biology 13: 443-452.

Cannon, L.R.G. and Jennings, J.B. 1987. Occurrence and nutritional relationships of four ectosymbiotes of the freshwater crayfishes Cherax dispar Riek and Cherax punctatus Clark (Decapoda: Parastacidae) in Queensland. Australian Journal of Marine and Freshwater Research 38: 419-427.

Chapman, D.G. 1952. Inverse, multiple and sequential sample censuses. Biometrics December 1952: 286-306.
Chiew, F.H.S. and McMahon, T.A. 2002. Modelling the impacts of climate change on Australian streamflow. Hydrological Processes 16: 1235-1245.

Clark, E. 1936. Notes on the habits of land crayfishes. Victorian Naturalist 53: 65-68.

Clark, E. 1937. The life history of the Gippsland crayfish. Australian Museum Magazine, June 1937: 186-192.

Correia, A.M. 1993. Population dynamics of Procambarus clarkil (Crustacea: Decapoda) in Portugal. Freshwater Crayfish 8: 276-290.

Coughran, J. 2000. The Distribution, Habitat and Conservation Status of Euastacus gumar (Decapoda: Parastacidae), in Northeastern New South Wales. BAppSc (Hons) Thesis, School of Resource Science and Management, Southern Cross University.

Coughran, J. 2006a. Biology of the Freshwater Crayfishes of Northeastern New South Wales, Australia. Ph.D. Thesis, School of Environmental Science and Management, Southern Cross University.

Coughran, J. 2006b. Field Guide to the Freshwater Crayfishes of Northeastern New South Wales. Natureview Publishing, Bangalow, NSW.

Coughran, J. and Leckie, S. 2007. Euastacus pilosus n. sp., a new crayfish from the highland forests of northern New South Wales, Australia. Fishes of Sahul 21:309-316.

Coughran, J., Leckie, S. and Gartside, G. 2008. Distribution, habitat and conservation status of the freshwater crayfishes, Cherax cuspidatus (Riek) and C. leckii (Coughran) (Decapoda: Parastacidae). Freshwater Crayfish 16: 19-26

France, R.J., Holmes, J. and Lynch, A. 1991. Use of sizefrequency data to estimate the age composition of crayfish populations. Canadian Journal of Fisheries and Aquatic Sciences 48: $2324-2332$ 
Furse, J.M. and Wild, C.H. 2004. Laboratory moult increment, frequency, and growth in Euastacus sulcatus, the Lamington Spiny Crayfish. Freshwater Crayfish 14: 205-211.

Goldman, C.R. and Rundquist, J.C. 1977. A comparative ecological study of the California Crayfish, Pacifastacus leniusculus (Dana), from two subalpine lakes (Lake Tahoe and Lake Donner). Freshwater Crayfish 3: 51-80.

Guan, R. and Wiles, P.R. 1996. Growth, density and biomass of crayfish, Pacifastacus leniusculus, in a British lowland river. Aquatic Living Resources 9: 265-272.

Hamr, P. 1992. Embryonic and postembryonic development in the Tasmanian freshwater crayfishes Astacopsis gouldi, Astacopsis franklinii and Parastacoides tasmanicus tasmanicus (Decapoda: Parastacidae). Australian Journal of Marine and Freshwater Research 43: 861-878.

Hamr, P. 1997. A giant's tale: the life history of Astacopsis gouldi (Decapoda: Parastacidae) a freshwater crayfish from Tasmania. Freshwater Crayfish 11: 13-33.

Hamr, P. and Richardson, A. 1994. Life history of Parastacoides tasmanicus tasmanicus Clark, a burrowing freshwater crayfish from south-western Tasmania. Australian Journal of Marine and Freshwater Research 45: 455-70.

Hartnoll, R.G. 1983. Strategies of Crustacean growth. Australian Museum Memoirs 18: 121-131.

Hennessy, K. 2006. Climate change scenarios for initial assessment of risk in accordance with risk management guidance. Commonwealth Scientific and Industrial Research Organization, Australia. Available online at http://www.greenhouse.gov.au/ impacts/publications/risk-scenarios.html

Honan, J.A. 1998. Egg and juvenile development of the Australian freshwater crayfish, Euastacus bispinosus Clark (Decapoda: Parastacidae). Proceedings of the Linnean Society of N.S.W. 119: 37-54.

Honan, J.A. and Mitchell, B.D. 1995a. Catch characteristics of the large freshwater crayfish Euastacus bispinosus Clark (Decapoda: Parastacidae), and implications for management. Freshwater Crayfish 10: 57-69.

Honan, J.A. and Mitchell, B.D. 1995b. Growth of the large freshwater crayfish Euastacus bispinosus Clark (Decapoda: Parastacidae). Freshwater Crayfish 10: 118-131.

Honan, J.A. and Mitchell, B.D. 1995c. Reproduction of Euastacus bispinosus Clark (Decapoda: Parastacidae), and trends in the reproductive characteristics of freshwater crayfish. Marine and Freshwater Research 46: 485-99.

Hopkins, C.L. 1966. Growth in the freshwater crayfish, Paranephrops planifrons White. New Zealand Joumal of Science 9: 50-56.

Hopkins, C.L. 1967. Breeding in the freshwater crayfish Paranephrops planifrons White. New Zealand Journal of Marine and Freshwater Research 1: 51-58.

Horwitz, P. 1990. The conservation status of Australian freshwater crustacea. Australian National Parks and Wildlife Service Report Series, No. 14: 1-121.

Horwitz, P. 1995. The conservation status of Australian freshwater crayfish: review and update. Freshwater Crayfish 10: 70-80.

Howden, M. 2003. Climate trends and climate change scenarios. Pp. 8-13 in Climate Change Impacts On Biodiversity In Australia, edited by M. Howden, L. Hughes, M. Dunlop, I. Zethoven, D. Hilbert and C. Chilcott. Outcomes of a workshop sponsored by the Biological Diversity Advisory Committee, 1-2 October 2002, Commonwealth of Australia, Canberra.
Hutchings, R. 1988. A review of the Australian freshwater crayfish fauna with reference to aquaculture. Freshwater Crayfish 7: 13-18.

Johnson, H.T. 1982. Synopsis of biological data on the freshwater crayfish Euastacus spinosus Riek. NSW State Fisheries Internal Report.

Jones, T.C. and Lester, G.J. 1993. Aspects of the biology and pathogenicity of Diceratocephala boschmai (Platyhelminthes: Temnocephalida), an ectosymbiont on the Redclaw crayfish, Cherax quadricarinatus. Australian Journal of Marine and Freshwater Research 44: 927-933.

Lake, P.S. and Sokol, A. 1986. Ecology of the yabby Cherax destructor Clark (Crustacea: Decapoda: Parastacidae) and its potential as a sentinel animal for mercury and lead pollution. Australian Water Resources Council Technical Paper No. 87. Australian Government Publishing Service, Canberra.

Land and Property Information NSW. 2000. Topoview. New South Wales Topographic Map Series 1969-1991. [CD-ROM]. State of New South Wales, Sydney.

Lappalainen, R. and Pursiainen, M. 1995. The estimation of a Noble Crayfish (Astacus astacus L.) population size. Freshwater Crayfish 8: 228-234.

Lintermans, M. and Rutzou, T. 1991. The Status, Distribution and Management of the Murray Crayfish Euastacus armatus in the Australian Capital Territory. (Research Report 6). Department of the Environment, Land and Planning, ACT Parks and Conservation Service.

McCormack, R.B. 2008. The Freshwater Crayfish of New South Wales Australia. Australian Aquatic Biological Pty. Ltd., Karuah, New South Wales.

Merrick, J.R. 1993. Freshwater Crayfishes of New South Wales. Linnean Society of New South Wales, Sydney.

Momot, W.T. 1967. Population dynamics and productivity of the crayfish, Orconectes virilis, in a Marl Lake. The American Midland Naturalist 78: 55-81.

Momot, W.T. 1984. Crayfish production: a reflection of community energetics. Journal of Crustacean Biology 4: 35-54.

Morey, J.L. 1988. Freshwater Crayfish Survey Latrobe River System October 1987. Central Gippsland Region, Department of Conservation, Forests and Lands.

Morey, J.L. 1998. Growth, catch rates and notes on the biology of the Gippsland spiny freshwater crayfish, Euastacus kershawi (Decapoda: Parastacidae), in west Gippsland, Victoria. Proceedings of the Linnean Society of New South Wales 119: 55-69.

Morey, J. and Hollis, G. 1997. Australia's most diverse crayfish habitat? Memoirs of the Museum of Victoria 56: 667-669.

Morgan, G.J. 1986. Freshwater Crayfish of the Genus Euastacus Clark (Decapoda: Parastacidae) from Victoria. Memoirs of the Museum of Victoria 47: 1-57.

Morgan, G.J. 1997. Freshwater crayfish of the genus Euastacus Clark (Decapoda: Parastacidae) from New South Wales, with a key to all species of the genus. Records of the Australian Museum Supplement 23: 1-110.

New South Wales National Parks and Wildlife Service. 2001. Hygiene Protocol for the Control of Disease in Frogs. Information Circular No. 6. NSW National Parks and Wildlife Service, Hurstville, NSW.

Pratten, D.J. 1980. Growth in the crayfish Austropotamobius pallipes (Crustacea: Astacidae). Freshwater Biology 10: 401-412. 
Ricker, W.E. 1975. Computation and Interpretation of Biological Statistics of Fish Populations. Department of the Environment Fisheries and Marine Service, Ottawa.

Riek, E.F. 1969. The Australian freshwater crayfish (Crustacea: Decapoda: Parastacidae) with descriptions of new species. Australian Journal of Zoology 17: 855-918.

Schnabel, Z.E. 1938. The estimation of the total fish population of a lake. American Mathematical Monthly 45: 348-352.

Shipway, B. 1951. The natural history of the marron and other fresh water crayfishes of south-western Australia. Part 2. Western Australian Naturalist 3(2): 27-34.

Smith, G.C., Borsboom, A., Lloyd, R., Lees, N. and Kehl, J. 1998. Habitat changes, growth and abundance of juvenile giant spiny crayfish, Euastacus hystricosus (Decapoda: Parastacidae), in the Conondale Ranges, south-east Queensland. Proceedings of the Linnean Society of New South Wales 119: 71-86.

Suter, P.J. 1977. The biology of two species of Engaeus (Decapoda: Parastacidae) in Tasmania II. Life history and larval development, with particular reference to E. cisternarius. Australian Journal of Marine and Freshwater Research 28: 85-93.
Turvey, P. and Merrick, J.R. 1997a. Reproductive biology of the freshwater crayfish, Euastacus spinifer (Decapoda: Parastacidae), from the Sydney region, Australia. Proceedings of the Linnean Society of New South Wales 118: 131-155.

Turvey, P. and Merrick, J.R. 1997b. Moult increments and frequency of the freshwater crayfish, Euastacus spinifer (Decapoda: Parastacidae), from the Sydney region, Australia. Proceedings of the Linnean Society of New South Wales 118: 187-204.

Turvey, P. and Merrick, J.R. 1997c. Growth with age of the freshwater crayfish, Euastacus spinifer (Decapoda: Parastacidae), from the Sydney region, Australia. Proceedings of the Linnean Society of New South Wales 118: 205-215.

Whitmore, N. and Huryn, A.D. 1999. Life history and production of Paranephrops zealandicus in a forest stream, with comments about the sustainable harvest of a freshwater crayfish. Freshwater Biology 42: 467-478. 